\title{
HEALTH EFFECTS IN A MODEL OF SECOND-BEST ENVIRONMENTAL TAXATION OR RECONSIDERING "RECONSIDERING THE TAX-INTERACTION EFFECT"
}

\author{
Roberton C. Williams III \\ Working Paper 8048 \\ http://www.nber.org/papers/w8048 \\ NATIONAL BUREAU OF ECONOMIC RESEARCH \\ 1050 Massachusetts Avenue \\ Cambridge, MA 02138
}

December 2000

The author would like to thank Larry Goulder and Ian Parry for helpful comments. The views expressed in this paper are those of the author and not necessarily those of the National Bureau of Economic Research.

(C) 2000 by Roberton C. Williams III. All rights reserved. Short sections of text, not to exceed two paragraphs, may be quoted without explicit permission provided that full credit, including $(\subset$ notice, is given to the source. 
Health Effects in a Model of Second-Best Environmental Taxation or

Reconsidering "Reconsidering the Tax-Interaction Effect"

Roberton C. Williams III

NBER Working Paper No. 8048

December 2000

JEL No. H21, H23, I18, J22

\begin{abstract}
$\underline{\text { ABSTRACT }}$
The literature on environmental taxation in the presence of pre-existing distortionary taxes has shown that the interactions with pre-existing taxes tend to raise the cost of an environmental tax, and thus that the optimal environmental tax in that context is less than marginal environmental damages. A recent paper by Schwartz and Repetto (2000) challenges this finding, arguing that the health benefits from reduced pollution will also interact with pre-existing taxes, possibly causing the optimal environmental tax to exceed marginal environmental damages.

Schwartz and Repetto's analysis aimed to account for health effects by representing environmental quality and leisure as substitutes in utility. The present paper employs an analytically tractable general equilibrium model that, in contrast with Schwartz and Repetto's analysis, explicitly considers health effects. It shows that interactions with health effects from pollution actually will tend to reduce the optimal environmental tax. This result contradicts Schwartz and Repetto's conclusion. This demonstrates the usefulness of explicitly modeling health effects, and it reinforces the general notion that tax-interactions tend to raise the costs of an environmental tax.
\end{abstract}

\author{
Roberton C. Williams \\ Department of Economics \\ University of Texas \\ Austin, TX 78712 \\ and NBER \\ rwilliam@eco.utexas.edu
}




\section{Introduction}

In recent years, a substantial body of research has focused on the question of how environmental policy should be set in an economy with pre-existing distortionary taxes, a question with significant policy importance. A number of previous papers have shown that interactions with pre-existing taxes raise the cost of environmental taxes. However, these papers did not account for impacts of changes in environmental quality on individual health. A recent paper by Schwartz and Repetto (2000) argues that, when health effects are accounted for, the optimal environmental tax may exceed the marginal damage from pollution. The present paper demonstrates that this is not the case.

Previous papers have pointed out two contrasting effects on the costs of environmental taxes in the presence of pre-existing distortionary taxes. Some early papers ${ }^{1}$ suggested that the cost of a pollution tax could be lower in such a context, because pollution tax revenue could replace revenue from distortionary taxes such as the income tax, and thus produce a welfare gain. This effect has come to be known as the revenue-recycling effect.

More recent papers ${ }^{2}$ demonstrated the existence of a second general-equilibrium effect, the tax-interaction effect, which works in the opposite direction. Pollution taxes drive up the price of consumption goods, thus lowering the real wage and discouraging labor supply. This exacerbates the tax distortion in the labor market, creating an efficiency loss. Thus, the tax-interaction effect tends to raise to costs of environmental taxes. These papers also show that this loss is larger than the gain from the revenue-recycling effect, because the pollution tax has a narrower base than the labor tax, and thus is less efficient at raising revenue. Consequently, in an economy with pre-existing distortionary taxes, the optimal pollution tax is typically lower than in an economy without such pre-existing taxes.

Schwartz and Repetto (2000) question this conclusion. They cite a large body of evidence suggesting that a significant portion of the cost of pollution comes in the form of damages to human health, and that such health damages tend to reduce labor supply. This

\footnotetext{
${ }^{1}$ See Terkla (1984), Lee and Misiolek (1986), Oates and Schwab (1988), Oates (1993), and Repetto et al. (1992).

${ }^{2}$ These papers include Bovenberg and de Mooij (1994), Goulder (1995), Bovenberg and Goulder (1996), Goulder et al. (1999) and Parry et al. (1999).
} 
evidence is used to justify assuming a preference structure in which leisure and environmental quality are substitutes, whereas the prior literature had assumed that environmental quality is separable in utility. Their paper then shows that when environmental quality is a leisure substitute, the optimal pollution tax will be higher than previous studies have indicated, and that it could easily exceed the level of marginal damages.

The present paper reexamines the implications of health effects from pollution. Rather than simply assuming a preference relationship, as in Schwartz and Repetto, it uses a model with an explicit representation of the ways in which health damages from pollution affect labor supply. ${ }^{3}$ In this model, health damage from pollution may affect labor supply through two distinct channels-by increasing spending on medical care, and/or by causing individuals to spend time sick, thus reducing the time they have available for labor or leisure.

The model confirms that health effects do indeed affect labor supply, and that this results in an additional impact, here termed the benefit-side tax-interaction effect. However, counter to Schwartz and Repetto's results, the model demonstrates that this effect cannot cause the optimal pollution tax to exceed marginal damages. In fact, it shows that, for typical parameter values, this effect will cause the optimal pollution tax to be even lower than that indicated by previous studies which assumed separability.

To the extent that health damage from pollution causes households to spend more on medical care, the benefits from reduced pollution are diminished by the benefit-side taxinteraction effect. Thus, the optimal pollution tax will be less than previous studies have indicated, and will be substantially below the marginal damage from pollution.

In contrast, to the extent that pollution causes increased time lost to illness, the sign of the benefit-side tax-interaction effect will be ambiguous, though for typical parameter values, this effect will diminish the benefits of regulation. Furthermore, even if parameter values are such that this effect does increase the benefits of regulation, the optimal pollution tax will still be unambiguously less than marginal damages. These results differ sharply from Schwartz

\footnotetext{
${ }^{3}$ This model and the analysis presented here draw heavily on Williams (2000), which analyzes the implications of health and productivity effects on second-best environmental taxation.
} 
and Repetto's conclusions, demonstrating the value of modeling such effects explicitly rather than assuming a preference relationship.

The next section of the paper presents an analytically tractable general-equilibrium model that explicitly models health damages from pollution, and derives expressions for the welfare effect from and optimal level of a pollution tax. The final section summarizes and concludes.

\section{The Model}

A representative agent model is assumed, where households divide their time endowment $(T)$ between leisure $(l)$ and labor $(L)$, which is used to produce the two consumption goods, $X$ and $Y$. Households divide their income between consumption of $X$ and $Y$ in order to maximize the utility function

$$
U(V(l, X, Y), H, G)
$$

which is continuous and quasi-concave. $G$ is the quantity of a public good, and $H$ represents consumer health.

$X, Y, G$, and medical care $(M)$ are all produced using labor as the only factor of production. All production is assumed to follow constant returns to scale, and units are normalized such that one unit of labor can produce one unit of any of the four goods.

$$
L=X+Y+M+G
$$

Pollution from consumption of good $X$ reduces environmental quality. Good $Y$ is nonpolluting. Environmental quality is simply equal to an exogenous baseline level minus emissions, with units normalized such that the production and consumption of one unit of $X$ results in one unit of emissions:

$$
Q=\bar{Q}-X
$$

Pollution has two effects. First, consumer health depends on environmental quality and the level of medical care consumed.

$$
H=H(M, Q)
$$

It is assumed that $\partial H / \partial M>0, \partial H / \partial Q>0, \partial^{2} H / \partial M^{2}<0$, and $\partial^{2} H / \partial M \partial Q<0$. 
Second, pollution causes households to lose some time to sickness, thus reducing the time they have available for work or leisure. This implies the following household time constraint

$$
L+l=T-S(Q)
$$

where $S(Q)$ represents time spent sick, which is decreasing in $Q$.

The government levies a corrective tax on $\operatorname{good} X$, and also imposes a tax on labor income. We normalize the gross wage to equal one, which yields the consumer budget constraint

$$
\left(1-\tau_{L}\right) L+I=\left(1+\tau_{X}\right) X+Y+M
$$

where $I$ is lump-sum income, which is assumed to be zero. ${ }^{4}$

Revenue from the two taxes is used to finance provision of the public good. ${ }^{5}$ For simplicity, we assume that the level of the public good is fixed. ${ }^{6}$

$$
G=\tau_{L} L+\tau_{X} X
$$

Households maximize utility (1) subject to their time constraint (5) and budget constraint (6), taking the quantity of the public good, the tax rates, and the level of environmental quality as given. This yields the first order conditions:

$$
U_{V} V_{X}=\left(1+\tau_{X}\right) \lambda ; U_{V} V_{Y}=\lambda ; U_{V} V_{l}=\left(1-\tau_{L}\right) \lambda ; U_{H} \frac{\partial H}{\partial M}=\lambda
$$

where $\lambda$ represents the marginal utility of income.

These first-order conditions, together with the other equations given thus far, implicitly define the uncompensated demand functions:

$$
X\left(\tau_{X}, \tau_{L}, Q, I\right) ; Y\left(\tau_{X}, \tau_{L}, Q, I\right) ; l\left(\tau_{X}, \tau_{L}, Q, I\right) ; M\left(\tau_{X}, \tau_{L}, Q, I\right)
$$

\footnotetext{
${ }^{4}$ The reader may wonder why the budget constraint includes $I$, given that households do not have any lump-sum income. This is necessary in order to provide a rigorous expression for income effects later in the paper.

${ }^{5}$ If government revenue were instead used to provide a fixed lump-sum transfer to households, as in Schwartz and Repetto (2000), the model's results would be unchanged, as long as the value of the transfer is held constant in real terms.

${ }^{6}$ Assuming instead that the government provides the optimal level of the public good would substantially complicate the analysis. The paper's results, however, would be qualitatively the same.
} 
Taking a total derivative of utility with respect to the corrective tax $\left(\tau_{X}\right)$, substituting in the consumer first-order conditions, dividing through by $\lambda$, and using $d G=0$ yield

$$
\frac{1}{\lambda} \frac{d U}{d \tau_{X}}=\left(1+\tau_{X}\right) \frac{d X}{d \tau_{X}}+\frac{d Y}{d \tau_{X}}+\frac{d M}{d \tau_{X}}+\left(1-\tau_{L}\right) \frac{d l}{d \tau_{X}}+\frac{1}{\lambda} \frac{\partial U}{\partial H} \frac{\partial H}{\partial Q} \frac{d Q}{d \tau_{X}}
$$

Taking a total derivative of the production equation (2), substituting in a total derivative of the household time constraint (5), and using $d G=0$ and $d T=0$

$\frac{d X}{d \tau_{X}}+\frac{d Y}{d \tau_{X}}+\frac{d M}{d \tau_{X}}+\frac{d l}{d \tau_{X}}+\frac{\partial S}{\partial Q} \frac{d Q}{d \tau_{X}}=0$

Subtracting (11) from (10) and rearranging, using $d Q=-d X$, yield

$$
\frac{1}{\lambda} \frac{d U}{d \tau_{X}}=\left(\tau_{X}-\tau_{P}\right) \frac{d X}{d \tau_{X}}-\tau_{L} \frac{d l}{d \tau_{X}}
$$

where $\tau_{P}$ is the Pigouvian tax level, equal to the marginal damage from pollution

$$
\tau_{P}=\frac{1}{\lambda} \frac{\partial U}{\partial H} \frac{\partial H}{\partial Q}-\frac{\partial S}{\partial Q}
$$

Expression (12) shows that the welfare effect of the policy depends on its effects in the two distorted markets.

Taking a total derivative of the household time constraint (5), adding a total derivative of the government budget constraint (7), and rearranging, using $d G=0, d T=0$, and

$$
\begin{aligned}
& \frac{d l}{d \tau_{X}}=\frac{\partial l}{\partial \tau_{X}}+\frac{\partial l}{\partial \tau_{L}} \frac{d \tau_{L}}{d \tau_{X}}+\frac{\partial l}{\partial Q} \frac{d Q}{d \tau_{X}} \text { give } \\
& \text { (14) } \frac{d l}{d \tau_{X}}=\frac{L \frac{\partial l}{\partial \tau_{X}}-\frac{\partial l}{\partial \tau_{L}}\left(X+\tau_{X} \frac{d X}{d \tau_{X}}-\tau_{L} \frac{\partial S}{\partial Q} \frac{d Q}{d \tau_{X}}\right)+L \frac{\partial l}{\partial Q} \frac{d Q}{d \tau_{X}}}{L-\tau_{L} \frac{\partial l}{\partial \tau_{L}}}
\end{aligned}
$$

Define

$$
\eta=\frac{\tau_{L} \frac{\partial l}{\partial \tau_{L}}}{L-\tau_{L} \frac{\partial l}{\partial \tau_{L}}}+1
$$


This is the marginal cost of public funds (MCPF), or the cost to the household of raising one dollar of government revenue through the labor tax. The numerator in the first term is the marginal deadweight loss in the labor market, while the denominator is the marginal revenue from a change in the tax rate. The cost to households is the deadweight loss plus the revenue; hence the MCPF is this first term plus one. This is a partial equilibrium definition of the MCPF; it ignores the effects of the labor tax on deadweight loss in the market for good X, revenue from the corrective tax, and environmental quality. We will assume that labor supply is not backward-bending and that marginal revenue from the labor tax is positive, which together imply that $\eta>1$.

Substituting (14) and (15) into (12) yields

$$
\frac{1}{\lambda} \frac{d U}{d \tau_{X}}=\underbrace{\left(\tau_{X}-\tau_{P}\right) \frac{d X}{d \tau_{X}}}_{d W^{P}}+\underbrace{(\eta-1)\left(X+\tau_{X} \frac{d X}{d \tau_{X}}\right)}_{d W^{R}}-\underbrace{\eta \tau_{L} \frac{\partial l}{\partial \tau_{X}}}_{d W^{I}}-\underbrace{\left[(\eta-1) \tau_{L} \frac{\partial S}{\partial Q}-\eta \tau_{L} \frac{\partial l}{\partial Q}\right] \frac{d Q}{d \tau_{X}}}_{d W^{I B}}
$$

This expression decomposes the welfare effect into four components: the primary welfare effect, $\left(d W^{P}\right)$, the revenue-recycling effect, $\left(d W^{R}\right)$, the (cost-side) tax-interaction effect $\left(d W^{I}\right)$, and the benefit-side tax-interaction effect $\left(d W^{I B}\right)$. The primary welfare effect is the effect of the tax on the pollution externality, equal to the wedge between the social cost of emissions (the Pigouvian tax) and the private cost (the tax on good $X$ ). The revenuerecycling effect is the efficiency gain from using pollution tax revenue to reduce the labor tax rate, which equals the marginal cost of public funds minus one times the marginal pollution tax revenue.

Finally, two tax-interaction effects result when the pollution tax alters households' labor supply decisions, thus altering the welfare loss from the income tax distortion in the labor market. ${ }^{7}$ The cost-side tax-interaction effect $d W^{I}$, which is by now well-known from the prior literature, results when the pollution tax drives up the costs of producing consumer goods, lowering the real wage and discouraging labor supply. The benefit-side taxinteraction effect $d W^{I B}$ expresses the impact of improved environmental quality on labor supply decisions.

\footnotetext{
${ }^{7}$ Schwartz and Repetto (2000) treated these two effects together, but this paper will treat them separately.
} 
Each of the two tax-interaction effects is equal to the distortionary wedge in the labor market (the income tax) times the change in leisure. Added to this is the gain or loss from changes in labor tax revenue, equal to the change in tax revenue times the marginal cost of public funds minus one. Summing those elements for the effect of the pollution tax on consumer good prices gives the third term in (22), and a similar sum for the change resulting from improved environmental quality gives the fourth term.

The prior literature (Parry (1995), for example) has shown that the cost of environmental regulation depends on the degree of substitutability between the polluting good and leisure. For simplicity, we consider the neutral assumption that good $X$ is an average substitute for leisure. Given this assumption, the cost-side tax-interaction effect can be expressed (see appendix for derivation) as

$$
d W^{I}=-(\eta-1) X
$$

The benefit-side tax-interaction effect can be expressed (see appendix for derivation) as

$$
d W^{I B}=-(\eta-1)\left[\tau_{L} \frac{\partial S}{\partial Q}+\frac{\varepsilon_{L I}}{\varepsilon_{L}}\left(1-\frac{\partial M}{\partial I}\right)^{-1}\left(\frac{\partial S}{\partial Q}\left(1-\tau_{L}\right)+\frac{\partial M}{\partial Q}\right)\right] \frac{d Q}{d \tau_{X}}
$$

where $\varepsilon_{L I}$ is the income elasticity of labor supply and $\varepsilon_{L}$ is the uncompensated labor supply elasticity. Examining this expression shows that if an improved environment results in lower spending on medical care, the benefit-side tax-interaction effect will reduce the benefit of regulation. In this case, environmental quality is a substitute for a private good (medical care), and thus increased environmental quality increases leisure consumption, causing a general-equilibrium welfare loss.

In contrast, if an improved environment results in less time lost to illness, then the sign of the benefit-side tax-interaction effect is ambiguous. Reducing time lost to illness increases both leisure demand and labor supply. The first term in brackets is the welfare gain that results because the increased labor supply boosts labor tax revenue. However, there is an offsetting welfare loss (part of the second term in brackets) because increased leisure demand 
exacerbates the labor market distortion. Therefore, the sign of the total effect is ambiguous, and depends on tax rates and elasticities. ${ }^{8}$

Substituting (17) and (18) into (16) and canceling terms yield

$$
\frac{1}{\lambda} \frac{d U}{d \tau_{X}}=\left(\eta \tau_{X}-\tau_{P}\right) \frac{d X}{d \tau_{X}}-(\eta-1)\left[\tau_{L} \frac{\partial S}{\partial Q}+\frac{\varepsilon_{L I}}{\varepsilon_{L}}\left(1-\frac{\partial M}{\partial I}\right)^{-1}\left(\frac{\partial S}{\partial Q}\left(1-\tau_{L}\right)+\frac{\partial M}{\partial Q}\right)\right] \frac{d Q}{d \tau_{X}}
$$

Setting this expression equal to zero and rearranging, using $d Q=-d X$, yield an expression for the optimal pollution tax

$$
\tau_{X}^{*}=\frac{\tau_{P}}{\eta}-\frac{(\eta-1)}{\eta}\left[\tau_{L} \frac{\partial S}{\partial Q}+\frac{\varepsilon_{L I}}{\varepsilon_{L}}\left(1-\frac{\partial M}{\partial I}\right)^{-1}\left(\frac{\partial S}{\partial Q}\left(1-\tau_{L}\right)+\frac{\partial M}{\partial Q}\right)\right]
$$

The first term on the right-hand side of this equation-the Pigouvian tax rate divided by the marginal cost of public funds-is the optimal environmental tax rate found by previous studies which assume that environmental quality is separable in utility. The second term represents the effect of benefit-side tax interactions.

Is it possible that the optimal pollution tax exceed the Pigouvian tax rate? For this to be the case, the term in brackets must exceed the Pigouvian tax rate. Inspection reveals that this is impossible. The second term in brackets is negative, and the first term is at most equal to the labor tax rate times the Pigouvian tax rate. Thus, Schwartz and Repetto's claim-that health effects may cause the optimal tax rate to exceed the Pigouvian level-is invalid.

But is the optimal pollution tax above the level suggested by most other prior work, which assumed that environmental quality is separable in utility. For this to be the case, the term in brackets must be positive. Assuming that the labor tax rate is 0.4 , the uncompensated labor supply elasticity is 0.15 , the income elasticity of labor supply is -0.15 , and that medical

\footnotetext{
${ }^{8}$ Schwartz and Repetto (2000) correctly noted that if pollution causes households to spend time sick, improvements in environmental quality will increase labor supply. However, contrary to their conclusion, this does not necessarily mean that there will be a gain from the benefit-side tax-interaction effect. It is easy to see the source of their error. In a model in which the total time available for labor and leisure is fixed-as in Schwartz and Repetto's study-an increase in labor supply requires a decrease in leisure consumption. Explicitly modeling this health impact, however, shows that both labor and leisure will increase in response to reduced pollution, and thus that the sign of the welfare impact is ambiguous.
} 
spending is not an inferior good ${ }^{9}$ implies that it is negative. Thus, if either type of health effect is present, the optimal tax will actually be lower than in a model in which environmental quality is separable in utility.

\section{Conclusions}

This paper has shown that when improved environmental quality reduces spending on medical care, the optimal environmental tax will be lower than indicated by models in which environmental quality is separable from goods and leisure in the utility function. A similar result will hold for typical parameter values when environmental quality affects time lost to illness, though it is possible for the optimal environmental tax to be higher if income effects on labor supply are quite small. In either case, the optimal environmental tax will be below the value of marginal damages from pollution.

These results run counter to those found by Schwartz and Repetto (2000). This demonstrates the value of explicitly modeling health effects, rather than assuming a preference relationship, and reinforces the general notion that pre-existing distortionary taxes tend to raise the costs of environmental taxes.

\footnotetext{
${ }^{9}$ These labor elasticities are roughly consistent with those found by Fuchs, Krueger, and Poterba (1998) in a survey of labor economists. A labor tax rate of 0.4 is a standard assumption in the literature; see, for example, Browning (1987).
} 


\section{References}

Bovenberg, A. Lans, and Ruud A. de Mooij, 1994. "Environmental Levies and Distortionary Taxation." American Economic Review 84(4):1085-9.

Bovenberg, A. Lans and Lawrence H. Goulder, 1996. "Optimal Environmental Taxation in the Presence of Other Taxes: General Equilibrium Analyses." American Economic Review 86:985-1000

Bovenberg, A. Lans and Lawrence H. Goulder, 2000. "Environmental Taxation and Regulation in a Second-Best Setting" in A. Auerbach and M Feldstein, eds., Handbook of Public Economics, second edition, Amsterdam: North-Holland, forthcoming

Browning, Edgar K., 1987. "On the Marginal Welfare Cost of Taxation." American Economic Review 77:11-23.

Fuchs, Victor R., Alan B. Krueger and James M. Poterba, 1998. "Economists' Views about Parameters, Values and Policies: Survey Results in Labor and Public Economics." Journal of Economic Literature 36(3): 1387-1425.

Goulder, Lawrence H., 1995. "Environmental Taxation and the 'Double Dividend': A Reader's Guide." International Tax and Public Finance 2(2):157-183.

Goulder, Lawrence H., Ian W. H. Parry, Roberton C. Williams III, and Dallas Burtraw, 1999. The Cost-Effectiveness of Alternative Instruments for Environmental Protection in a SecondBest Setting, Journal of Public Economics, 72:329-360.

Lee, Dwight R., and Walter S. Misiolek, 1986. "Substituting Pollution Taxation for General Taxation: Some Implications for Efficiency in Pollution Taxation." Journal of Environmental Economics and Management, 13:338-347.

Oates, Wallace E., 1993. "Pollution Charges as a Source of Public Revenues." In Herbert Giersch, ed., Economic Progress and Environmental Concerns. Berlin: Springer-Verlag, pp. $135-52$.

Oates, Wallace E., and Robert M. Schwab, 1988. "Economic Competition among Jurisdictions: Efficiency Enhancing or Distortion Inducing?" Journal of Public Economics 35:333-354, April.

Parry, Ian W. H., 1995. "Pollution Taxes and Revenue Recycling." Journal of Environmental Economics and Management 29:S64-S77

Parry, Ian W. H., Roberton C. Williams III, and Lawrence H. Goulder, 1999. "When Can Carbon Abatement Policies Increase Welfare? The Fundamental Role of Distorted Factor Markets." Journal of Environmental Economics and Management, 37:52-84

Repetto, Robert, Roger C. Dower, Robin Jenkins, and Jacqueline Geoghegan, 1992. Green Fees: How a Tax Shift Can Work for the Environment and the Economy. World Resources Institute, November.

Schwartz, Jesse and Robert Repetto, 2000. "Nonseparable Utility and the Double Dividend Debate: Reconsidering the Tax-Interaction Effect" Environmental and Resource Economics, $15: 149-157$

Terkla, David, 1984. “The Efficiency Value of Effluent Tax Revenues.” Journal of Environmental Economics and Management 11:107-23. 
Williams, Roberton C., III, 2000. "Environmental Tax Interactions When Pollution Affects

Health or Productivity." working paper, University of Texas-Austin 


\section{Appendix}

\section{Derivation of Equation (17)}

The expression for the (cost-side) tax-interaction effect from equation (16) is:

(A1) $\quad d W^{I}=-\eta \tau_{L} \frac{\partial l}{\partial \tau_{X}}$

Because the change in the price of good $\mathrm{X}$ is equal to the change in the tax rate, the Slutsky equation gives

(A2) $\frac{\partial l}{\partial \tau_{X}}=\frac{\partial l^{C}}{\partial \tau_{X}}-\frac{\partial l}{\partial I} X$

where the superscript "C" denotes a compensated derivative.

Similarly,

(A3) $\frac{\partial l}{\partial \tau_{L}}=\frac{\partial l^{C}}{\partial \tau_{L}}-\frac{\partial l}{\partial I} L$

Taking a derivative of the household utility function (1), holding the levels of utility and of environmental quality constant and substituting in the consumer first-order conditions (11) yield

(A4) $\frac{\partial l^{C}}{\partial \tau_{L}}=-\frac{\partial l^{C}}{\partial\left(1-\tau_{L}\right)}=\frac{1+\tau_{X}}{1-\tau_{L}} \frac{\partial X^{C}}{\partial\left(1-\tau_{L}\right)}+\frac{1}{1-\tau_{L}} \frac{\partial Y^{C}}{\partial\left(1-\tau_{L}\right)}+\frac{1}{1-\tau_{L}} \frac{\partial M^{C}}{\partial\left(1-\tau_{L}\right)}$

The assumption that the cross-elasticity between $\mathrm{X}$ and leisure is equal to the average (weighted by consumption share) over all goods can be written as

$$
\frac{\partial X^{C}}{\partial\left(1-\tau_{L}\right)} \frac{1-\tau_{L}}{X}=\frac{1}{\left(1+\tau_{X}\right) X+Y+M}\left(\left(1+\tau_{X}\right) X \frac{\partial X^{C}}{\partial\left(1-\tau_{L}\right)} \frac{1-\tau_{L}}{X}+Y \frac{\partial Y^{C}}{\partial\left(1-\tau_{L}\right)} \frac{1-\tau_{L}}{Y}+M \frac{\partial M^{C}}{\partial\left(1-\tau_{L}\right)} \frac{1-\tau_{L}}{M}\right)
$$

Substituting (A5) and the household budget constraint (6) into (A4) yields

(A6) $\frac{\partial l^{C}}{\partial \tau_{L}}=\frac{\partial X^{C}}{\partial\left(1-\tau_{L}\right)} \frac{L}{X}$

Finally, the Slutsky symmetry property gives

(A7) $\frac{\partial l^{C}}{\partial \tau_{X}}=\frac{\partial X^{C}}{\partial\left(1-\tau_{L}\right)}$

Substituting (A2), (A3), (A6), (A7) and the definition of $\eta$ (15) into (A1) yields equation (17).

Derivation of Equation (18) 
The expression for the benefit-side tax-interaction effect from equation (16) is:

(A8) $d W^{I B}=-\left[(\eta-1) \tau_{L} \frac{\partial S}{\partial Q}+\eta \tau_{L} \frac{\partial l}{\partial Q}\right] \frac{d Q}{d \tau_{X}}$

The change in spending on $X, Y$, and $l$ for a change in $I$ will equal

(A9) $\quad\left(1-\tau_{L}\right) \frac{\partial l}{\partial I}+\left(1+\tau_{X}\right) \frac{\partial X}{\partial I}+\frac{\partial Y}{\partial I}=1-\frac{\partial M}{\partial I}$

For a change in $Q$ that change will be

(A10) $\left(1-\tau_{L}\right) \frac{\partial l}{\partial Q}+\left(1+\tau_{X}\right) \frac{\partial X}{\partial Q}+\frac{\partial Y}{\partial Q}=-\left(1-\tau_{L}\right) \frac{\partial S}{\partial Q}-\frac{\partial M}{\partial Q}$

Weak separability of health in the utility function implies that leisure demand is determined solely by the relative prices of $l, X$, and $Y$ (which are not affected by changes in $Q$ ) and by the amount spent on those goods. Together with (A9) and (A10), this implies

(A11) $\frac{\partial l}{\partial Q}=-\frac{\partial l}{\partial I}\left(1-\frac{\partial M}{\partial I}\right)^{-1}\left(\frac{\partial S}{\partial Q}\left(1-\tau_{L}\right)+\frac{\partial M}{\partial Q}\right)$

The uncompensated labor supply elasticity is

(A12) $\varepsilon_{L}=\frac{\partial L}{\partial\left(1-\tau_{L}\right)} \frac{1-\tau_{L}}{L}=\frac{\partial l}{\partial \tau_{L}} \frac{1-\tau_{L}}{L}$

and the income elasticity of labor supply is

(A13) $\varepsilon_{L I}=\frac{\partial L}{\partial I} \frac{\left(1-\tau_{L}\right) L}{L}=-\frac{\partial l}{\partial \tau_{L}}\left(1-\tau_{L}\right)$

Substituting expressions (A11) through (A13) and the definition of the MCPF (15) into (A8) and rearranging yields equation (18) 